Article

\title{
Analysing the Impact of the Glass Ceiling in a Managerial Career: The Case of Spain
}

\author{
Rosa M. Yagüe-Perales *(D), Pau Pérez-Ledo (D) and Isidre March-Chordà \\ Department of Applied Economics, University of Valencia, 46010 València, Spain; papele@uv.es (P.P.-L.); \\ isidre.march@uv.es (I.M.-C.) \\ * Correspondence: yague@uv.es
}

Citation: Yagüe-Perales, R.M.; Pérez-Ledo, P.; March-Chordà, I. Analysing the Impact of the Glass Ceiling in a Managerial Career: The Case of Spain. Sustainability 2021, 13, 6579. https://doi.org/10.3390/ su13126579

Academic Editors: Mónica Segovia Pérez and Eva Cifre

Received: 25 April 2021

Accepted: 2 June 2021

Published: 9 June 2021

Publisher's Note: MDPI stays neutral with regard to jurisdictional claims in published maps and institutional affiliations.

Copyright: (c) 2021 by the authors. Licensee MDPI, Basel, Switzerland. This article is an open access article distributed under the terms and conditions of the Creative Commons Attribution (CC BY) license (https:/ / creativecommons.org/licenses/by/ $4.0 /)$.

\begin{abstract}
The need to break down the barriers facing women in the labour market arouses great interest for reasons of social and sustainability justice. This study breaks new ground on the topic of the "glass ceiling" by assessing the evolution of gender inequality in the proportion of individuals reaching high managerial positions. The application of the csQCA method to a survey of two cohorts of Spanish graduates in management sharing the same starting conditions reveals two factors: job variety and additional education, as conditions that are usually present in a successful managerial career. Our findings confirm the prevalence of the gender gap with little progress in recent years. Women find it more difficult to promote to high managerial positions whereas being a man turns out to almost be a guarantee for eluding low managerial positions. In the context of Spain, and for sure in most other countries, the few women attaining high managerial positions still need to make a greater effort in their professional career than their male counterparts.
\end{abstract}

Keywords: management; gender; gap; labour

\section{Introduction}

The term "glass ceiling" refers to the barriers that women face to obtaining executive positions. These barriers, which are often invisible, hinder many women with high qualifications and professional capacity from accessing the highest levels of leadership and responsibility in the same conditions as those of men.

The interest of the gender glass ceiling is indubitable. From a social sustainability approach, women's empowerment has been promoted in the 2030 Agenda for Sustainable Development [1] adopted by the United Nations (UN) General Assembly as a proactive way to increase a sustainable economic growth. In this regard, Sustainable Development Goal (SDG) 5 seeks to "achieve gender equality and empower all woman and girls as a necessary foundation for a peaceful, prosperous and sustainable world" [2]. Beyond social and labour justice reasons, the promotion of women to executive positions would bring benefits to the management and competitiveness of organisations [2].

The presence of women in top management positions in both public and private organizations is significantly lower than that of men. However, despite the growing concern at the social level, very few studies thus far have precisely quantified the scope of this gap.

Many women willing to develop a professional career in the managerial field suffer from discrimination in job promotion. This glass ceiling preventing women from attaining positions of maximum responsibility and business leadership can be of three types: selfimposed, institutional or organizational barriers [3].

The few studies in the field convey that gender diversity in top management is helpful in activating dynamic capabilities and setting up a culture oriented towards collaboration and experimentation [4]. Moreover, female executives tend to promote more flexible and innovative companies [5]. 
This study is intended to shed new light on the participation of women and on changes over time in an especially significant labour market segment, i.e., management in Spain, a country in which the difficulties for women to attain executive positions might still be hampered by the prevalence of a dominant "patriarchal worldview" in Spanish society and culture [3].

The vast majority of existing studies on the gender glass ceiling exclusively refer to gender earnings or, at most, to the presence of women on boards of directors. Despite having some data available [6], there is little data on the accessibility of top managerial positions such as CEOs or departmental directors.

This study will precisely address this gap by delving into the gender differences in the proportion of professionals attaining high managerial positions. To confirm the presence and scope of this gap, we will conduct empirical fieldwork with respondents sharing the same starting educational background and age, in order to avoid any bias and ensure total comparability.

The main purpose of this research is to assess the degree of gender inequality in terms of top management positions attained by a set of professionals totally comparable with respect to their age and educational level. The aim is to identify and measure the presence of a gender gap in a management professional career. We will presume that attaining top managerial positions is a goal generally pursued by the majority of professionals working in the private sector and holding a management degree from a university. Therefore, our survey will contain only graduates working in the private sector.

We have divided our main objective into the following specific ones:

- To find out the factors associated with professional success in the managerial area,

- $\quad$ To discover the presence and scope of the glass ceiling in Spain against women in the managerial area, and

- $\quad$ To calibrate the pace at which this gap has been reduced over time.

Our study attempts to prove how the careers of professionals sharing exactly the same starting conditions (in terms of age, education and origin) diverges between men and women, hence verifying the prevalence of a labour gap against women in the field of management.

Our findings will confirm the presence and scope of this management gap. The reasons underlying this gap, which probably include a broad variety of social, familiar and personality factors $[7,8]$, are beyond the scope of this study.

We pose the hypothesis that the professional career of women in the most recent cohorts of graduates becomes closer to that of their male counterparts and, consequently, we expect the gender gap to tend to dilute in the most recent graduates in comparison to the eldest cohort.

This study is expected to highlight to what extent the gap in the aspirations and job/life preferences of young women and men with a management background is lower now than it was in the same cohorts of professionals 10 years older. The longitudinal nature of the empirical fieldwork will allow us to measure the pace at which the reduction of the gender gap in leadership attainment amongst professionals from the field of management has been taking place since the late 1990s until today.

Our empirically-based study will make significant contributions to a poorly explored field. Firstly, our results confirm the long period of time needed in order to underpin a successful career in the managerial field. Secondly, we have identified two remarkable factors linked to success, regardless of gender. Thirdly, similar to other recent studies, we confirm the prevalence of a gender gap [8-11]. In addition, we reveal the evolution over a 10-year period and display the factors behind these changes. Finally, our analysis of the role of a LinkedIn profile confirms the growing importance of being active in this network for the youngest generations of professionals in the field of management. 


\subsection{Theoretical Framework}

\subsubsection{Explaining the Gender Gap}

Gender role theory can be used to explain the causes of the disparities between women and men in income earnings. In the workplace, women earn less income and accrue less wealth than do men in nearly every occupation [12], due at least partially to bias in performance assessments.

Gender roles consist of both descriptive norms, which are shared expectations about the ways in which men and women actually behave, labelled as gender stereotypes [7]. These stereotypes tend to link women with more socially-oriented, assistive and sympathetic tasks, whereas men are more often associated with agentic characteristics such as being task-oriented, competitive, ambitious and independent [8].

Connected with these different orientations, women tend to face more obstacles to ascending in their career paths in the field of management, such as becoming leaders [7].

In this line, a study conducted by Sheppard (2018) [13] on US undergraduate students shows that female students perceived themselves to be having less leadership ability than that of male students, and viewed their attainment of leadership roles as being less likely than that of male participants, which could reflect anticipated discrimination.

Female participants reported less interest in elite leadership managerial positions and were also less likely to accept a promotion that would require them to sacrifice enjoyable work.

Sheppard (2018) [13] concludes that women emphasised the importance of life attribute preferences (family, good health), whereas male participants emphasised the importance of job attribute preferences (high salary).

Functional job analysis methodology classifies occupations between those focused on tasks ("things" and "data") and those focused on relationships ("people") [14]. Similarly, leadership styles are often categorised into task-oriented leadership and relationshiporiented leadership [15]. The former tends to be more appreciated by men and the latter by women.

Carrasco-Santos et al. (2020) [9] state that despite the levels of education being similar or even higher in women than in men, the proportion of managerial positions occupied by women is substantially lower due to the presence of other determinants that prevent equality from being fulfilled. The majority of managerial positions demand a great availability of hours, and employers are reluctant to hire women because they usually assume more familial and domestic responsibilities, mainly childcare.

These self-imposed barriers linked to family-work-personal reconciliation lead to stereotypes about women, such as the lack of planning and lower flexibility levels [13,14].

As a result, women are assigned or prefer taking jobs with lower levels of responsibility, which is a phenomenon known as horizontal segregation, as well as part-time and temporary jobs to better reconcile work life with familial/personal life [9].

These arguments are probably behind the larger proportion of women working in the public sector than of men. In Spain, women represent $56.7 \%$ of all civil servants [16]. More specifically, $13 \%$ of men and $20 \%$ of women work in the public sector in Spain, a proportion that is $50 \%$ higher [17].

The diversity management approach attempts to empower workers and increase organisational efficiency by enhancing the differences between various types of members.

Research into the relationship between gender diversity-defined in this study as the share of women in management positions-and sustainability has produced mixed findings [18].

Several studies have found that the two are positively associated [19-22]. Meanwhile, some others have found no relationship between gender diversity in management and sustainability [23-26].

According to Schwartz-Ziv (2017) [27], the increase in women's participation in the labour market following the introduction of gender quotas is expected to have a positive impact. 
In contrast, Kenneth et al. (2012) [28] report a negative impact on the value of the company consequent to the introduction of quotas. According to the authors, the increase in both governance costs and leverage has caused a deterioration of the operational performance of companies.

The dynamic capabilities approach expects higher benefits and advantages in more heterogeneous and diverse teams.

In this stream of the literature, the studies supporting a direct relationship between women in board positions and better corporate and financial performance prevail.

The involvement of women in high-performance teams is a source of heterogeneity flows with a positive impact on a firm's innovativeness by promoting flexibility and smoother communication flows $[5,8,29]$. In addition, when women assume the role of chairperson, firms tend to implement more actively equal gender policies [2] and corporate social responsibility policies [30,31].

According to [32], broadening the representation of women in management in SMEs has a wider societal contribution by improving the sustainability of firms.

The literature analysing the impact of gender diversity on corporate governance has yielded mixed results.

The discrimination against women is due to erroneous beliefs regarding the capacity of women. Therefore, the presence of women on many boards of directors is merely testimonial and the percentage of female directors (around $4 \%$ ) is substantially lower than that of female managers, which seems to indicate an underrepresentation of women on boards [33].

Women's communication style tends to be more participatory, process-oriented, and more driven by consumers' interests. The inclusion of women on boards of directors eases the access of women to executive positions and is well received by clients and investors [34]

Villamil and Alonso (2003) [35] claim that the incorporation of women on boards of directors has a direct influence on the productivity and creativity of governing bodies.

Similarly, Krishnan and Parsons (2007) [36] state that the presence of women in the executive management of large firms had a positive impact on the IPO process.

On the contrary, Quintana García (2016) [4], found that a larger proportion of women in top management teams of biotech firms from the USA were connected with lower chances of attaining a successful IPO.

The study conducted by Provasi and Harasheh (2020) [37], based on Italy, concludes that gender diversity enhanced better governance by fostering more responsible thinking and creating a dynamic environment. However, an over-concentration of a certain gender might offset the positive impact of diversity and increase the cost of governance.

\subsubsection{Data on the Gender Labour Gap}

This section offers an updated review of the gender differences in the labour market.

Gender statistics are needed in order to measure and monitor the realities of the lives of women and men, and of girls. A broad diversity of topics and issues are covered under the heading of gender statistics, reflecting the changing roles of women and men in society, in the economy as well as in families and households.

Gender statistics help policymakers to formulate and monitor policies and plans and monitor changes and trends.

Table 1 summarises some key figures comparing Spain and the EU-28 with respect to a few key indicators regarding gender employment. 
Table 1. Employment by gender.

\begin{tabular}{ccc}
\hline \multicolumn{3}{c}{ Employment Rate by Gender: \% Population Aged 20 to 65 } \\
\hline Country & Total: 2005-2017 & Women: 2005-2017 \\
\hline EU-28 & $67.9-72.2$ & $60.0-66.5$ \\
\hline Spain & $67.5-65.5$ & $55.1-59.6$ \\
\hline Employment rate of recent graduates (\% of population aged 20 to 34 with at least upper-secondary education) \\
\hline EU-28 & $78.9-80.2$ & $76.6-78.4$ \\
\hline Spain & $82.9-71.9$ & $80.1-73.3$ \\
\hline
\end{tabular}

Source: UNECE gender statistics database (2019).

Starting with the evolution of the employment rate by gender (\% population aged 20 to 65) for the period 2005-2017, Spain experienced an increase in the employment rate of women from $55.1 \%$ in 2005 to $59.6 \%$ in 2017, in line with the EU-28 growing from $60.0 \%$ to $66.5 \%$.

The deep economic slump experienced by Spain during the period between 2008 and 2013 has caused a reduction in the overall employment rate of recent graduates, in front of a slight increase in the EU-28. The reduction of women has been lower than that of young graduate men.

The gender overall earnings gap is a synthetic indicator used by Eurostat. It measures the impact of three combined factors-(1) the average hourly earnings, (2) the monthly average of the number of hours paid (before any adjustment for part-time work), and (3) the employment rate-on the average earnings of all women of working age (whether employed or not employed) in comparison to men.

According to the European Commission (2018) [6], the behaviour of Spain with regard to this indicator has been positive, with a remarkable reduction in the gap between 2002 and 2014 from $55.4 \%$ to merely $35.7 \%$. This reduction has been smoother in the EU-28, from $44.8 \%$ to $40.5 \%$. Accordingly, the earnings gap by gender is still significant, albeit lower now in Spain than in the EU-28.

Table 2 informs of several variables of great interest regarding the gender gap in managerial occupations.

Table 2. Gender gap in management.

\begin{tabular}{ccc}
\hline Variables Variables & EU-28 & Spain \\
\hline Women in managerial occupations & $35 \%$ & $23.4 \%$ \\
\hline Gender pay gap in management & $37 \%$ & $16.2 \%$ \\
\hline Women on boards of large listed companies (2017) & $25.3 \%$ & $22 \%$ \\
\hline Change in the share of women on boards (2010-2017) & $+13.4 \%$ & $+12.5 \%$ \\
\hline Source: Eurostat gender statistics (2018).
\end{tabular}

Source: Eurostat gender statistics (2018).

Compared to the EU-28, the participation of Spanish women in managerial occupations is almost 12 points down the European average.

The underrepresentation of women in top management positions in Spain is generalised, even in those sectors with a higher number of women at work, such as the hotel subsector, with senior management positions being dominated by men [9].

In contrast, the gender earnings gap in management positions is much lower in Spain than in the EU-28. While Spanish women receive on average 16.2\% lower pay than do men, this difference scales up to $37 \%$ in Europe.

The representation of women on the boards of the largest listed companies in the EU is similar in Spain and in the whole of Europe, as it is the increase in the share of women on these boards. 
Our empirical fieldwork delves into the managerial career of professionals from the Spanish region of Valencia. Some data that is worth noting is provided next.

The gap against women in the annual pay of professionals with tertiary education was $10.82 \%$ in the Valencian region in 2018, much lower than the Spanish average of $20.40 \%$, as well as dropping significantly from $32.72 \%$ in 2006 . This reduction is much broader in Valencia than in the whole of Spain (from 34.09\% to 20.40\%) [17].

Regarding the jobs held, the gap in director/manager positions increased to $14.02 \%$, still below the $20.75 \%$ in Spain and dropping from $22.22 \%$ in 2006. Regarding technical jobs, the gap is $10.29 \%$, in front of $27.25 \%$ in 2006 , revealing the broadest reduction over time. Finally, administrative positions retain the highest gender pay gap: $25.17 \%$ in 2018 , in front of $35.02 \%$ in 2006 [17].

From this review we derive the following propositions:

Proposition 1: In comparison to women, men attain higher management positions in the organisations in which they work.

Proposition 2: The advantage of men over women in holding high managerial occupations tends to dilute in the new generations. Differences in favour of men across younger cohorts are significantly lower than amongst more mature professionals.

Proposition 3: Graduates in the field of management need more than 10 years of a professional career to attain top managerial positions. Accordingly, the proportion of executives amongst graduates aged around 35 years is expected to be substantially lower than amongst those 10 years older.

\subsubsection{Other Factors Influencing Professional Success in Management}

Besides gender, other factors can have a significant impact on managerial careers.

One variable worth analysing for its potential impact on professional prospects is the variety of jobs and positions.

Job transfers within firms might be viewed as being costly because the productivity of workers temporarily declines until they become accustomed to a new job. However, job variety and the learning value of a job have been found to be positively connected to employability [38].

Job variety throughout a career path is a positive professional sign when each new job results in a better work position. Notwithstanding, unskilled workers also tend to change jobs often, hence becoming a sign of inefficiency.

Overall, in the field of management, job variety tends to be positively appraised. Top executives and CEOs perceived to be successful usually receive improved offers from other corporations; therefore, a broader rotation of jobs can be viewed as being proof of a promising and rising career.

Following this brief review of the topic, we derive our next proposition:

Proposition 4: Individuals accounting for a broader job variety during their professional career hold more chances of occupying higher managerial occupations.

In connection with the importance of gaining knowledge and being updated so as to succeed professionally, another factor worth analysing is that of additional qualifications or training.

The term "lifelong learning" (LLL) refers to consistency in learning over one's life in and beyond formal educational settings, which means that there are many common ways in which learning takes place [39]. To continue education and acquire necessary skills is increasingly important in adapting to the ever-changing world.

Continuing education (CE), professional development and LLL are synonyms that all refer to an educational or training process that is essential for an organisation to succeed [39].

CE refers to the knowledge and new skills that people learn in a continuous way in school, at home, on the job or in the community.

In this study we will consider both formal learning and non-formal education. The former is defined as the learning that occurs in an organised and structured context (formal 
education, in-company training). This type is designed as learning and may lead to formal recognition (diploma, certificate).

Non-formal education refers to gathering education, training or professional development (arranged by educational institutions and training organisations) in society. It is more adjustable to a student's needs but (according to the programme) does not always lead to a formal certificate.

$\mathrm{CE}$ in organisations is a valuable way in which to enhance the skills and knowledge of the workforce, whereas individuals use CE for upward career movement, job enhancement and personal enrichment [40].

$\mathrm{CE}$ is expected to impact positively on improving the professional competence of professionals and staffing. CE allows constant improvement in the level of competence of professionals and upgrades the chances of attaining better jobs in the labour market.

From these arguments we derive our next proposition:

Proposition 5: Individuals more proactive in the acquisition of continuing education and accounting for broader lifelong learning are expected to attain higher management positions.

The presence in professional social networks has an increasing impact on the chances of finding better job opportunities. LinkedIn is (undoubtedly) the social network most deeply rooted amongst management professionals.

The main goal of using LinkedIn is to find job opportunities and create professional connections with colleagues and potential customers [41,42].

The majority of studies intending to observe gender differences in online self-presentation, as is the case with LinkedIn, have relied on social role theory [43-45], which holds that gender differences result from the diverse social roles occupied by men and women, which can vary between societies and historical periods [46].

In general, men are more likely than women to advertise their status, both online and offline [47].

LinkedIn internally analyses the differences (by gender) in the use of its platform.

The following is a profile emerging from LinkedIn's own analysis, extracted by the end of 2018, regarding gender professional differences:

- Women tend to promote themselves and their successes less than men,

- Men tend to include more information in their LinkedIn profile,

- Men have larger networks on LinkedIn than their female counterparts,

- $\quad$ Men tend to highlight more senior-level experience, often removing junior-level roles, and

- Women are more likely to have shorter profile summaries.

From here we derive our final proposition:

Proposition 6: Proactivity on the LinkedIn network enhances the chances of attaining upper-management positions. Men are more active than women on this network and, consequently, men's chances of attaining higher positions in management are increased.

\section{Materials and Methods}

\subsection{Data and Variables}

The fieldwork consists of a database that contains data from 170 individuals holding the same degree in Business Administration from the Faculty of Economics at the University of Valencia in Spain. The survey covers two cohorts of graduates, corresponding to two promotions, separated 10 years apart: those having graduated in the period from 1997-1999 and with an average age of 45 years by the time of the survey, and those having graduated in the period from 2007-2009 and with an average age of 35 years

In Spain, graduates in the field of Business Administration need between 5 and 10 years to specialise in a specific management area and promote themselves in the labour market. In addition, a 10-year period between two promotions is sufficiently broad to observe changes in the pattern of employability. In our survey, younger graduates are not 
included because they are still acquiring experience and are far from reaching a definitive or stable professional status.

The proportions of men and women in the survey are almost even, with 88 men and 82 women.

One additional trait shared by the respondents is that of having an active profile on LinkedIn, which is a professional social network. After monitoring a broader list of graduates we conclude that no more than $30 \%$ of all the graduates in the same school of Business in the period from 1997-1999 had an account open on LinkedIn. The proportion only increases slightly to $35-40 \%$ for those graduating 10 years later. In contrast, the presence on LinkedIn of individuals graduating from the same business school in the last 5 years is estimated to be above $60 \%$. The proportion of male graduates on LinkedIn is only slightly higher than that of female graduates in both promotions.

The outcome variable in our model of analysis is the professional success attained in the field of management by the surveyed individuals, all of whom graduated from the same business school and are working in the private sector and with a profile open on LinkedIn.

Professional success is a highly qualitative and subjective term around which no consensus on their meaning and implications exists. Given the lack of a widely accepted definition of professional success in the managerial field, an individual is defined in this study as being professionally successful when he/she currently holds a position of CEO, main founder or departmental director in a private company not described as being a microfirm. In contrast, this study attributes absence of professional success to positions of administrative or area manager.

This variable will be predicted using a series of conditions derived from the proposed theoretical framework.

The description of the outcome and the conditions of the model are stated in Table 3.

Table 3. Professional success: outcome and conditions.

\begin{tabular}{ll}
\hline Success: Professional Success & \multicolumn{1}{c}{ Outcomes } \\
\hline JobV: Job variety & $\begin{array}{l}\text { Presence: CEO, Main Founder, Departmental Director } \\
\text { Absence: Administrative, Area Manager }\end{array}$ \\
\hline Link: LinkedIn profile & \multicolumn{1}{c}{ Conditions } \\
\hline Gender & High variety of jobs and short span of time in last job/the opposite \\
\hline AcProm: Academic promotion & Proactive use of LinkedIn, profile, contacts/low LinkedIn profile \\
\hline AddTrain: Additional training & Men/women \\
\hline
\end{tabular}

The model's dependent variable, defined as "outcome", is "professional success", which can take two possible values:

- $\quad$ 0: a lack of success, when the individual has reached administrative or area manager positions at most; and

- 1: success, when the individual has reached a top management position as either a main founder, CEO or departmental director in a company not classified as a microfirm.

The explanatory variables or conditions have been extracted from the theoretical framework.

As the main purpose of this study is to determine the existence and extent of a glass ceiling against women in the managerial field, the key variable or condition in our model will be gender. 
From Table 4 and at a descriptive level, a couple of remarkable differences emerge by gender.

Table 4. Descriptive statistics of the "men" sample and "women", matched control group.

\begin{tabular}{|c|c|c|c|c|}
\hline \multirow{2}{*}{$\begin{array}{c}\text { Total } \\
\text { Variables }\end{array}$} & \multicolumn{2}{|c|}{ Men } & \multicolumn{2}{|c|}{ Women } \\
\hline & Frequency (N) & Percentage & Frequency (N) & Percentage \\
\hline Gender & 88 & $51.8 \%$ & 82 & $48.2 \%$ \\
\hline \multicolumn{5}{|c|}{ Professional level } \\
\hline 1: Administrative: $\mathrm{N}: 87$ & 33 & $37.5 \%$ & 54 & $65.9 \%$ \\
\hline Prom1: 32-Prom2: 55 & $10-23$ & $23.3 \%-51.1 \%$ & $22-32$ & $59.5 \%-71.1 \%$ \\
\hline 2: Manager/director: N: 83 & 55 & $62.5 \%$ & 28 & $34.1 \%$ \\
\hline Prom1: 48 & $33-22$ & $76.7 \%-48.9 \%$ & $15-13$ & $40.5 \%-28.9 \%$ \\
\hline \multicolumn{5}{|c|}{ Academic promotion } \\
\hline 1: 1997-1999: N: 80 & 43 & $48.9 \%$ & 37 & $45.1 \%$ \\
\hline 2: 2007-2009: N: 90 & 45 & $51.1 \%$ & 45 & $54.9 \%$ \\
\hline \multicolumn{5}{|c|}{ LinkedIn profile } \\
\hline 1: Short: N: 77 & 35 & $39.8 \%$ & 42 & $51.2 \%$ \\
\hline Prom2: 49 & $12-23$ & $27.9 \%-51.1 \%$ & $16-26$ & $43.2 \%-57.8 \%$ \\
\hline 2: Broad: N: 93 & 53 & $60.2 \%$ & 40 & $48.8 \%$ \\
\hline Prom2: 41 & $31-22$ & $72.1 \%-48.9 \%$ & 21-19 & $56.8 \%-42.2 \%$ \\
\hline \multicolumn{5}{|c|}{ Variety of jobs } \\
\hline 1: Short: N: 67 & 32 & $36.4 \%$ & 35 & $42.7 \%$ \\
\hline 2: Broad: N: 103 & 56 & $63.6 \%$ & 47 & $57.3 \%$ \\
\hline \multicolumn{5}{|c|}{ Additional qualification } \\
\hline 1: Not: N: 81 & 42 & $47.7 \%$ & 39 & $47.6 \%$ \\
\hline Prom1: $37 \quad$ Prom2: 44 & $18-24$ & $41.9 \%-53.3 \%$ & $19-20$ & $51.4 \%-44.4 \%$ \\
\hline 2: Yes: N: 89 & 46 & $52.3 \%$ & 43 & $52.4 \%$ \\
\hline Prom1: $43 \quad$ Prom2: 46 & $25-21$ & $58.1 \%-46.7 \%$ & $18-25$ & $48.6 \%-55.6 \%$ \\
\hline
\end{tabular}

Firstly, the professional level attained by men clearly overtakes that attained by women. Almost two in three men in the sample have reached the manager/director level, whereas the proportion amongst women drops down to merely one third. This result suggests the existence of a glass ceiling against women. The analysis conducted next will statistically determine the extent of this difference.

The other variable with disparities worth mentioning by gender is the LinkedIn profile. The proportion of men with a broad and more complete profile on this professional social network is relatively higher $(60 \%)$ than that of women $(49 \%)$. The significance of this difference will be checked in a further statistical analysis.

For the variable "variety of jobs" the disparity is small and in favour of men, whereas no differences have been found with regard to "additional qualification".

The analysis at the level of promotions reveals that the vast majority of men from the first promotion $(76.7 \%$ ) have attained high managerial positions. The proportion of "successful" women is practically half of the aforementioned figure (40.5\%). As expected, the proportion of successful graduates from the most recent promotion is lower. However, the differences against women largely remain, with merely $28.9 \%$ (in front of $48.9 \%$ of men). 


\subsection{Model and Method}

The empirical analysis conducted is expected to explain the presence or absence of professional success in our survey of individuals graduating in Business Administration, based on the following model:

Success $=\mathrm{f}$ (Gender, JobV, Link, AcProm, AddTrain)

What characterises our empirical model is not the isolated effect of the selected variables but rather their combination in different causal configurations.

In our view, explaining our outcome: professional success in management requires a multidimensional approach, leading to identifying the conditions linked to either the presence or the absence of success based on a multidimensional approach.

The method employed in this study is a qualitative comparative analysis (QCA). This method is increasingly used to study phenomena that are "best understood as clusters of interconnected structures and practices, rather than as modular or loosely coupled entities whose components can be understood in isolation" [48].

QCA is an analytical technique grounded in set theory that enables identification of the causal conditions that lead to an outcome. The technique is useful for analysing causal processes under conditions of high causal complexity and can be used to find causes that combine to bring about outcomes [48].

Unlike standard regression methods, in QCA, constructs are measured using calibrated sets that reduce sample dependence. Set membership is defined according to substantive knowledge rather than to the sample mean, thereby reducing the importance of sample representativeness [48].

Unlike conventional methods (e.g., regression analysis), when predicting a dependent variable such as "professional success", QCA can identify several conditions in predicting an outcome of interest occurring.

The next step is to calibrate the measures of these characteristics by assigning membership to a condition [49]. After the values of antecedents are transformed into set membership, a truth table is generated which provides a list of combinations of the conditions that lead to the focal outcomes [50]. The variables of the model are used as the causal conditions.

The crisp-set form of QCA (csQCA) is the one used in this study. This technique is particularly suitable when working with small samples and dichotomous variables. csQCA was the first technique developed [51] based on Boolean algebra. This technique works with clear sets (crisp sets), wherein the only possibilities are the absence or presence of the conditions. The result is a binary form of reality, wherein cases either are or are not members of a set [52].

The first step in performing csQCA is the dichotomisation of the variables considered in the analysis, including the outcome. The next step comprises analysing the necessary and sufficient conditions in order to learn what they are and understand their relationship with the outcome.

\section{Results}

A complete implementation of csQCA is presented for each of the proposed models. The empirical analysis can be interpreted as explaining the presence or absence of each outcome based on the causal conditions. Consistent with the theoretical framework, the necessary and sufficient conditions are examined in relation to the presence of each outcome in our samples.

First, we performed an analysis of necessary conditions for the outcomes of professional success. In Model 1, the outcome variable is that of professional success in management of the surveyed people. The five conditions are included in the model, which can be expressed as follows:

Success $=\mathrm{f}$ (Gender, JobV, Link, Prom, AddTrain)

(a) In the analysis of necessary conditions for a professional level, the presence of the causal conditions was considered. 
(b) In the analysis of necessary conditions for a non-professional level, the absence of the causal conditions was considered.

As Table 5 shows, no condition exceeded the threshold of 1 . Accordingly, no single condition explained the presence or absence of our outcome in the observed cases. However, cslink (consistency $=0.72$ ) appeared to be a remarkable condition for the presence of professional success.

Table 5. Descriptive statistics of the "men" sample and "women", matched control group.

\begin{tabular}{ccccc}
\hline \multirow{2}{*}{ Construct } & \multicolumn{2}{c}{$\begin{array}{c}\text { Professional Level (a) } \\
\text { Consistency }\end{array}$} & $\begin{array}{c}\text { Non-Professional Level (b) } \\
\text { Coverage }\end{array}$ & $\begin{array}{c}\text { Consistency } \\
\text { Coverage }\end{array}$ \\
\hline csprom & 0.578 & 0.6 & 0.367 & 0.4 \\
$\sim$ csprom & 0.421 & 0.388 & 0.632 & 0.611 \\
csgender & 0.662 & 0.625 & 0.379 & 0.375 \\
$\sim$ csgender & 0.337 & 0.341 & 0.62 & 0.658 \\
cslink & 0.722 & 0.645 & 0.379 & 0.354 \\
c cslink & 0.277 & 0.298 & 0.62 & 0.701 \\
csjobv & 0.65 & 0.58 & 0.448 & 0.419 \\
$\sim$ csjobv & 0.349 & 0.376 & 0.551 & 0.623 \\
csaddtrain & 0.698 & 0.651 & 0.356 & 0.348 \\
$\sim$ csaddtrain & 0.301 & 0.308 & 0.356 & 0.348 \\
\hline
\end{tabular}

This finding is relevant in that it suggests that no condition in Table 5 seems to limit or prevent professional success in the surveyed individuals, all of whom graduated in Business Administration.

Following the recommendation of the csQCA method, and in order to determine to what extent the factor of gender is hampering the chances of women attaining professional success, an analysis of sufficient conditions is performed next.

The Quine-McCluskey algorithm was used for the analysis of sufficiency, and the intermediate solution was the one selected for being the most commonly used solution in QCA [53].

Table 6 shows the intermediate solution for the outcome of "professional success". In the three configurations stated, the consistency level surpassed the minimum threshold established by [54].

Table 6. Analysis of sufficiency: graduated with and without professional success (intermediate solution).

\begin{tabular}{|c|c|c|c|}
\hline Outcomes & Raw Coverage & Unique Coverage & Consistency \\
\hline \multicolumn{4}{|l|}{ 6a. Outcome: Professional success } \\
\hline $\mathrm{I} \sim \mathrm{cs}$ prom ${ }^{*} \mathrm{cs}$ gen ${ }^{*} \mathrm{cs}$ jobv ${ }^{*} \mathrm{cs}$ addtrain & 0.07228 & 0.01204 & 1 \\
\hline II $\sim$ cs prom $*$ cs link $*$ cs jobv ${ }^{*}$ cs addtrain & 0.09638 & 0.03614 & 1 \\
\hline III * cs gen * cs link* cs jobv * cs addtrain & 0.20481 & 0.14457 & 1 \\
\hline IV cs prom ${ }^{*}$ cs gen ${ }^{*} \sim \operatorname{cs}$ link ${ }^{*} \sim \mathrm{cs}$ jobv ${ }^{*}$ cs addtrain & 0.01204 & 0.01204 & 1 \\
\hline \multicolumn{4}{|l|}{ Solution coverage: 0.265} \\
\hline \multicolumn{4}{|l|}{ Solution consistency: 1} \\
\hline \multicolumn{4}{|l|}{ Frequency cut-off: 1} \\
\hline \multicolumn{4}{|l|}{ Consistency cut-off: 1} \\
\hline \multicolumn{4}{|l|}{ 6b. Outcome: Non-professional success } \\
\hline $\mathrm{V} \sim \mathrm{cs}$ gen $* \sim$ cslink $* \sim$ csaddtrain $* \sim \mathrm{cs}$ jobv & 0.13793 & 0.0459 & 1 \\
\hline VI $\sim$ csprom $* \sim$ cs link $* \sim$ cs addtrain $* \sim$ cs jobv & 0.13793 & 0.0459 & 1 \\
\hline VII $\sim$ csprom $* \sim$ csgen $* \sim$ cs addtrain $* \sim \mathrm{cs}$ jobv & 0.12643 & 0.0344 & 1 \\
\hline VIII cs prom ${ }^{*}$ cs gen ${ }^{*} \sim$ cslink ${ }^{*}$ cs addtrain ${ }^{*} \sim \mathrm{cs}$ jobv & 0.01149 & 0.0114 & 1 \\
\hline IX cs prom $* \sim$ csgen $*$ cs link $* \sim$ cs addtrain $*$ cs jobv & 0.01149 & 0.0114 & 1 \\
\hline \multicolumn{4}{|l|}{ Solution coverage: 0.2413} \\
\hline \multicolumn{4}{|l|}{ Solution consistency: 1} \\
\hline \multicolumn{4}{|l|}{ Frequency cut-off: 1} \\
\hline \multicolumn{4}{|l|}{ Consistency cut-off: 1} \\
\hline
\end{tabular}


Sub-Table $6 \mathrm{a}$ and $\mathrm{b}$ present the causal configurations that lead to high rates of individuals graduating in management with and without professional success in the region of Valencia.

These outcomes may also be due to the presence or absence of other conditions. Nevertheless, the emergence of different configurations suggests that more than one pattern can lead to a successful management career in the region of Valencia. In addition, the pathways do not refer to a single condition, but rather to a combination of factors that lead to the presence or absence of successful management in graduates from the University of Valencia.

Sub-Table 6a shows four solutions that lead to management success. As the main purpose of this study is to verify whether gender is a condition explaining professional success in management, we will focus on solutions I, III and IV.

Solution I suggests that professional success is linked to men from the first promotion holding a broad job variety and additional education.

Solution III connects professional success with the following profile: men who are proactive on LinkedIn, with a broad job variety and with additional education.

Solution IV links professional success with being a man from the youngest promotion and with additional education. This model displays the sufficient conditions for success in the younger graduates in our survey. For this cohort of professionals the proactive LinkedIn profile and the job variety are no longer sufficient conditions for success.

In short, our analysis determines that the variable "men" appears in all of the solutions.

Solution II is the only one not connected with the gender gap. Professional success can be achieved regardless of gender, provided that a proactive LinkedIn profile, a variety of jobs and additional education are ensured.

As expressed in sub-Table $6 \mathrm{~b}$, for the absence of management success we have found that for solutions V to IX, all of them except for solution VI include the gender variable.

The model provides the sufficient conditions for working in a managerial job with a low profile, mainly at the administrative level, which we associate with a lack of professional success in a management career.

Solution V suggests the following combination of conditions for the absence of professional success: a woman with a low LinkedIn profile, without additional education and with a low job variety. Similarly, solution VI connects the lack of success with older graduates, regardless of their gender and lacking the other factors.

Solution VII suggests the lack of professional success to be determined by being a woman who graduated in the eldest promotion and (again) without additional education and with a low job variety.

Solution VIII displays a completely different profile because it is the only one referring to men and younger graduates. The lack of success occurs with the following profile: men who graduated in 2007-2009, with a low LinkedIn profile, and with a low job variety (despite holding additional education).

Finally, solution IX suggests that the lack of professional success happens for younger women without additional training (despite holding a broad LinkedIn profile and having a high job variety).

For the absence of success it is worth remarking that the female gender appears in all but one of the combinations of conditions.

We expect to find differences in the profile that lead to the presence of success between the first and second promotions under study. For that reason, we have run two more models with the same variables, with one for each promotion.

Model promotion 1999:

Success $=\mathrm{f}$ (Gender, JobV, Link, AddTrain)

Algorithm: Quine-McCluskey

Concerning the eldest cohort of graduates, the variables of job variety and additional education are the most remarkable, as they appear in the two combinations of sufficient conditions connected with professional success. 
As stated in Table 7, the advantage of men over women only happens in one combination of variables.

Table 7. Analysis of sufficiency: graduated in 1999 with professional success (intermediate solution).

\begin{tabular}{cccc}
\hline Outcome & Raw Coverage & Unique Coverage & Consistency \\
\hline Outcome: Professional success & & & \\
$I^{*} \operatorname{cs}$ gen ${ }^{*} c s$ jobv ${ }^{*}$ cs addtrain & 0.171429 & 0.0285714 & 1 \\
$\mathrm{II}^{*}$ cs link ${ }^{*}$ cs jobv ${ }^{*}$ cs addtrain & 0.228571 & & \\
Solution coverage: 0.257 & & \\
Solution consistency: 1 & & \\
Frequency cut-off: 1 & & \\
Consistency cut-off: 1 & & \\
\hline
\end{tabular}

Note: $\left(^{*}\right)$ logical operator 'and'. Direct expectations $(1,1,1,1)$.

In the second one, success can be attained regardless of the gender and provided that a broad LinkedIn profile is also ensured.

Model promotion 2009:

Success $=\mathrm{f}$ (Gender, JobV, Link, AddTrain)

Algorithm: Quine-McCluskey

Our model referring to the cohort of the youngest graduates in the survey yields only one combination of sufficient conditions for professional success: men with a broad LinkedIn profile and with a job variety and additional education. Table 8 remarks that the only difference with the eldest cohort lies in the emergence of the LinkedIn profile as an additional sufficient condition.

Table 8. Analysis of sufficiency: graduated in 2009 with professional success (intermediate solution).

\begin{tabular}{|c|c|c|c|}
\hline Outcome & Raw Coverage & Unique Coverage & Consistency \\
\hline $\begin{array}{c}\text { Outcome: Professional success } \\
\mathrm{I}^{*} \text { cs gen }{ }^{*} \text { cs link }{ }^{*} \text { cs jobv }{ }^{*} \text { cs addtrain } \\
\text { Solution coverage: } 0.271 \\
\text { Solution consistency: } 1 \\
\text { Frequency cut-off: } 1 \\
\text { Consistency cut-off: } 1\end{array}$ & 0.25 & 0.25 & 1 \\
\hline
\end{tabular}

Note: $\left(^{*}\right)$ logical operator 'and'. Direct expectations $(1,1,1,1)$.

\section{Discussion}

Starting with Proposition 1, and due to the prevalence of a glass ceiling, we expected men to attain higher management positions than those of women in the organisations in which they work.

Our analysis states that no one single condition turns out to be necessary in order to attain professional success, and not one of them in isolation prevents these professionals from attaining top management positions.

This finding is outstanding for the purpose of our study, as it means that "gender" is not a necessary condition, alone, leading to a non-successful management professional career. The presence of women in top management positions, despite being lower than that of men, reaches a threshold that is large enough not to accept gender as an obstacle insurmountable for them.

This finding means that gender, in the case of being a factor hampering the chances of attaining professional success, fails to reach the status of being a necessary condition for the lack of success. However, our analysis also reveals that being a woman is a condition occurring in the majority of the sufficient combinations that leads to lower professional performance. 
On the contrary, the variable "men" appears in all of the sufficient solutions connected to success. From this result and the previous descriptive analysis, we can derive that being a woman seems to behave as a barrier to a successful professional career in management.

The most outstanding profile linked to a successful professional career is being a man, regardless of their promotion, being proactive on LinkedIn or having a broad job variety and additional education.

For a woman to attain professional success, all of the starting conditions need to be met: holding a proactive LinkedIn profile, a broad variety of jobs and additional education.

In line with the previous literature [8-11], our study confirms that women find it more difficult to be promoted to high managerial positions. On the contrary, being a man turns out to be almost a guarantee of eluding low managerial positions. Three out of five combinations leading to lower professional performance play against women, in front of merely one combination of factors connected with men: having graduated in 2007-2009, having a low LinkedIn profile, and having a short job variety (despite holding additional education).

Women tend to devote less time to setting up contacts and building a network helpful for their promotion.

All of these results lead us to confirm to a large extent the fulfilment of Proposition 1.

Proposition 2 expects lower divergences by gender in the most recent graduates. If confirmed, it would imply the dilution of the glass ceiling over time at a significant pace. Proposition 3 takes for granted a lower proportion of executives amongst graduates aged below 35 years than amongst those 10 years older.

In order to more precisely identify any changes over time, we have run two models with the csQCA method, with one for each cohort of graduates.

Our results confirm that men from the first promotion holding a broad job variety and additional education is a profile leading to professional success.

The findings remark broad job variety and additional education as being sufficient conditions for success amongst men from the eldest promotion, whereas the only sufficient condition in younger male graduates is additional education. However, it is worth observing that the proportion of successful graduates from the latest promotion is substantially lower than in the eldest one, especially amongst men. Of all the men qualified as successful professionals, $60 \%$ pertain to the first promotion and $40 \%$ to the second one. The differences amongst women are smaller, i.e., $54 \%$ vs. $46 \%$. A more precise way in which to examine this is by comparing the percentage of graduates from each promotion having attained a high managerial position, with an outstanding $76.7 \%$ of all men from the eldest promotion (in front of the $48.9 \%$ from the youngest promotion).

Professional success is more difficult for women and the advantage of the first promotion over the second one is smaller than amongst men. In our survey, $40.5 \%$ of women from the first promotion are "successful" in comparison to $28.9 \%$ from the second one.

Being a woman and lacking further education are key factors preventing younger graduates from attaining higher managerial positions. For them, a broad LinkedIn pro-file and a high job variety are not enough to attain professional success.

Our analysis of the eldest graduates yields two valid configurations of sufficient conditions leading to professional success. Job variety and additional education appear in both configurations, hence becoming the most remarkable traits of success in a managerial career. The male gender and a broad LinkedIn profile occur in merely one combination leading to success. Consequently, for the eldest cohort of graduates, being a man is a sufficient condition for success (provided that both job variety and additional education are ensured). Similarly, for a broad LinkedIn profile to play a role as a sufficient condition, regardless of being a man or woman, the other two variables must be met.

Women need to comply with all of the factors included in our model in order to have chances to succeed: holding a proactive LinkedIn profile, having a broad variety of jobs and additional education. This finding reveals that the few women having attained high managerial positions have needed to make a great effort in their professional career. 
Our results also state that being a woman and lacking further education are key factors preventing younger graduates from attaining higher managerial positions. For women, and differently from men, a broad LinkedIn profile and a high job variety are not enough to attain professional success. This finding reveals how difficult it is for women with no more than 10 years of professional experience and without additional training to attain high managerial positions.

After reviewing all of these results concerning Propositions 2 and 3, we conclude that no significant advances have been detected during the 10-year period from Promotion 1 to Promotion 2 in terms of a reduction of the gender gap in the context of management. Consequently, neither Proposition 2 nor 3 is confirmed by our study.

Moving on to Propositions 4 and 5, our study confirms that additional education and a broad job variety are the most outstanding conditions linked to professional success in the field of management. Their presence is sufficient for attaining higher managerial positions, whereas their absence is connected to a lack of professional success, regard-less of the promotion and the gender. Accordingly, these findings are of great value and lead us to confirm Propositions 4 and 5. In addition, these two factors reinforce each other, which means that their impact takes place together, not separately.

Proposition 6 expected proactivity on the LinkedIn network to enhance the chances of attaining upper-management positions. Our findings confirm this statement only for the younger promotion of professionals. The LinkedIn profile seems not to have played a remarkable role amongst the graduates with over 20 years of a professional career, as they have not needed to maintain an updated and broad LinkedIn profile to be promoted to top managerial positions.

The LinkedIn profile only appears in the combination of sufficient conditions for success in the youngest cohort of graduates. Therefore, this factor starts to become a primary factor linked to professional success from 2010 onwards.

Proposition 6 also expected men to be more active than women on this network. Our descriptive data confirm higher proactivity amongst men, but the difference with women is not broad. Consequently, and conversely to LinkedIn's own studies [48], our results do not allow us to confirm a connection between a more proactive LinkedIn profile and a higher proportion of men attaining higher positions in management.

\section{Conclusions}

In order to reduce and eventually dilute the gender gap, a change is needed regarding how society views women and, even better, how women view themselves in the field of management. Being aware of the barriers playing against women in a managerial career is a first step, but bringing about a change in the attitudes of companies at both institutional and organisational levels is even more urgent in order to make significant progress for a socially sustainable future. However, besides the changes at both societal and attitudinal levels (Quezada, 2018), the "glass ceiling" preventing women from attaining positions of business leadership will not be definitely lowered until the self-imposed barriers are totally overcome.

Our empirical fieldwork on a sample of graduates in Business Administration has allowed us to derive valuable findings on the evolution of the glass ceiling in the last years in the field of management in Spain.

From our findings, several significant contributions emerge:

- A management career in Spain is long and demanding. Usually more than 15 years is needed in order to attain high positions, regardless of gender.

- Men find it easier than women in general to attain top management jobs. Consequently, the existence of a glass ceiling in the field of management remains.

- We have witnessed a reduction of the gender gap in the managerial career in the last years, albeit at a slow pace. 
- To hold more chances of attaining high professional positions in management, two conditions clearly stand out: high job variety and additional education and training. The lack of both factors clearly penalises the managerial career.

- Proactivity on the LinkedIn network appears to be a significant factor for success in management only for the younger generations, i.e., those entering the labour market from 2010 onwards.

This study is not free from limitations.

First and foremost, we used a sample drawn from one Spanish university. Graduates from the University of Valencia are largely representative of Spain; thus, the results from our survey can, to a certain extent, be generalised to the whole of Spain but not to other countries or cultures. Certainly, the homogeneity of the sample, with professionals of the same origin, educational level, and age, allows for a finer comparison but, in exchange, reduces the representativeness of our findings.

Future research can address this limitation by replicating the study with graduates from other universities and from private business schools in Spain.

Secondly, other factors linked to a professional career and additional personality traits might be included and analysed in future research.

Thirdly, the term "professional success" could be complemented by new accomplishments beyond the status in the company.

Finally, the proactivity of the LinkedIn profile could be more broadly detailed, as well as its impact on users' chances of employability.

In conclusion, with this study we break new ground with regard to the phenomenon of the glass ceiling from a poorly explored perspective: that of the accessibility of high positions in management. The remarkable findings obtained through our field-work encourage us to continue delving into this field.

Author Contributions: Conceptualization I.M.-C. and R.M.Y.-P.; methodology, R.M.Y.-P. and I.M.-C.; data curation, R.M.Y.-P. and P.P.-L.; original draft preparation I.M.-C. and P.P.-L.; writing-review and editing, I.M.-C. All authors have read and agreed to the published version of the manuscript.

Funding: This research received no external funding.

Institutional Review Board Statement: Not applicable.

Informed Consent Statement: Not applicable.

Data Availability Statement: Not applicable.

Conflicts of Interest: The authors declare no conflict of interest.

\section{References}

1. Assembly, G. Resolution Adopted by the General Assembly on 25 September 2015. 2015. Available online: https://www.un. org/en/development/desa/population/migration/generalassembly/docs/globalcompact/A_RES_70_1_E.pdf (accessed on 18 January 2021).

2. Furlotti, K.; Mazza, T.; Tibiletti, V.; Triani, S. Women in top positions on boards of directors: Gender policies disclosed in Italian sustainability reporting. Corp. Soc. Responsib. Environ. Manag. 2019, 26, 57-70. [CrossRef]

3. Gaete-Quezada, R. Acceso de las mujeres a los cargos directivos: Universidades con techo de cristal. Rev. CS 2018, 67-90. [CrossRef]

4. Quintana-García, C. Impacto de la mujer directiva en la salida a bolsa de empresas de alta tecnología: El efecto mediador de las patentes y el desarrollo de productos. Eur. Res. Manag. Bus. Econ. 2016, 22, 63-69. [CrossRef]

5. Herring, C. Does diversity pay?: Race, gender, and the business case for diversity. Am. Sociol. Rev. 2009, 74, 208-224. [CrossRef]

6. European Commission. Report on Equality between Women and Men in the EU 2018; Publications Office of the European Union: Luxembourg, 2018.

7. Eagly, A.H.; Karau, S.J. Role congruity theory of prejudice toward female leaders. Psychol. Rev. 2002, 109, 573. [CrossRef]

8. Kidder, D.L. The influence of gender on the performance of organizational citizenship behaviors. J. Manag. 2002, 28, 629-648. [CrossRef]

9. Carrasco-Santos, M.J.; Cristófol Rodríguez, C.; Royo-Rodríguez, E. Why Is the Spanish Hotel Trade Lagging So Far Behind in Gender Equality? A Sustainability Question. Sustainability 2020, 12, 4423. [CrossRef] 
10. Tur-Porcar, A.; Mas-Tur, A.; Belso, J.A. Barriers to women entrepreneurship. Different methods, different results? Qual. Quant. 2017, 51, 2019-2034. [CrossRef]

11. Segovia, M.; Figueroa, C. Mujer y Alta Dirección en el Sector Turístico; Síntesis: Madrid, Spain, 2015.

12. Miller, K.; Vagins, D.J. The Simple Truth about the Gender Pay Gap; AAUW: Washington, DC, USA, 2018.

13. Sheppard, L.D. Gender differences in leadership aspirations and job and life attribute preferences among US undergraduate students. Sex Roles 2018, 79, 565-577. [CrossRef]

14. Cronshaw, S.F. Functional job analysis. In The Handbook of Work Analysis: Methods, Systems, Applications and Science of Work Measurement in Organizations; Wilson, M.A., Bennett, W., Jr., Gibson, S.G., Alliger, G.M., Eds.; Publisher Taylor \& Francis Group: Oxfordshire, UK, 2012; pp. 265-280.

15. Bass, B.M. Task versus relations-oriented leadership. In Bass \& Stogdill's Handbook of Leadership; Simon and Schuster: New York, NY, USA, 1990; pp. 473-510.

16. Ministerio de Política Territorial y Función Pública. Available online: https://www.mptfp.gob.es/portal/prensa/actualidad/ noticias/2021/03/20210307.html (accessed on 15 April 2021).

17. Instituto Nacional de Estadística. Available online: https://www.ine.es/ (accessed on 15 April 2021).

18. Rao, K.; Tilt, C. Board composition and corporate social responsibility: The role of diversity, gender, strategy and decision making. J. Bus. Ethics 2016, 138, 327-347. [CrossRef]

19. Birindelli, G.; Iannuzzi, A.P.; Savioli, M. The impact of women leaders on environmental performance: Evidence on gender diversity in banks. Corp. Soc. Responsib. Environ. Manag. 2019, 26, 1485-1499. [CrossRef]

20. Ciocirlan, C.; Pettersson, C. Does workforce diversity matter in the fight against climate change? An analysis of Fortune 500 companies. Corp. Soc. Responsib. Environ. Manag. 2012, 19, 47-62. [CrossRef]

21. Kassinis, G.; Panayiotou, A.; Dimou, A.; Katsifaraki, G. Gender and environmental sustainability: A longitudinal analysis. Corp. Soc. Responsib. Environ. Manag 2016, 23, 399-412. [CrossRef]

22. Post, C.; Rahman, N.; Rubow, E. Green governance: Boards of directors' composition and environmental corporate social responsibility. Bus. Soc. 2011, 50, 189-223. [CrossRef]

23. Cucari, N.; Esposito de Falco, S.; Orlando, B. Diversity of board of directors and environmental social governance: Evidence from Italian listed companies. Corp. Soc. Responsib. Environ. Manag. 2018, 25, 250-266. [CrossRef]

24. Deschênes, S.; Rojas, M.; Boubacar, H.; Prud'homme, B.; Ouedraogo, A. The impact of board traits on the social performance of Canadian firms. Corp. Gov. 2015, 15, 293-305. [CrossRef]

25. Galbreath, J. Are there gender-related influences on corporate sustainability? A study of women on boards of directors. Organ. Manag. J. 2011, 17, 17-38. [CrossRef]

26. Schaper, M. The essence of ecopreneurship. Greener Manag. Int. 2002, 38, 26-30. [CrossRef]

27. Schwartz-Ziv, M. Gender and board activeness: The role of a critical mass. J. Financ. Quant. Anal. 2017, 52, 751-780. [CrossRef]

28. Ahern, K.R.; Dittmar, A.K. The changing of the boards: The impact on firm valuation of mandated female board representation. Q. J. Econ. 2012, 127, 137-197. [CrossRef]

29. Talke, K.; Salomo, S.; Rost, K. How top management team diversity affects innovativeness and performance via the strategic choice to focus on innovation fields. Res. Policy 2010, 39, 907-918. [CrossRef]

30. Yasser, Q.R.; Al Mamun, A.; Ahmed, I. Corporate social responsibility and gender diversity: Insights from Asia Pacific. Corp. Soc. Responsib. Environ. Manag. 2017, 24, 210-221. [CrossRef]

31. Setó-Pamies, D. The relationship between women directors and corporate social responsibility. Corp. Soc. Responsib. Environ. Manag. 2015, 22, 334-345. [CrossRef]

32. Graafland, J. Women in management and sustainable development of SMEs: Do relational environmental management instruments matter? Corp. Soc. Responsib. Environ. Manag. 2020, 27, 2320-2328. [CrossRef]

33. De Cabo, R.M.; Gimeno, R.; Escot, L. Discriminación en consejos de administración: Análisis e implicaciones económicas. Rev. Econ. Apl. 2010, 18, 131-162.

34. Daily, C.M.; Dalton, D.R. Women in the boardroom: A business imperative. J. Bus. Strategy 2003, 24. [CrossRef]

35. Villamil López, M.; Alonso Almeida, M.D.M. Position of women in management teams and growth of hotel chains worldwide. Estud. Turísticos 2013, 198, 35-60.

36. Krishnan, G.V.; Parsons, L.M. Getting to the bottom line: An exploration of gender and earnings quality. J. Bus. Ethics 2007, 78, 65-76. [CrossRef]

37. Provasi, R.; Harasheh, M. Gender diversity and corporate performance: Emphasis on sustainability performance. Corp. Soc. Responsib. Environ. Manag. 2021, 28, 127-137. [CrossRef]

38. Marzec, I.; Austen, A.; Fraczkiewicz-Wronka, A.; Zacny, B. The impact of job content on employability and job performance in public organizations. Int. J. Manpow. 2020. [CrossRef]

39. Laal, M.; Laal, A.; Aliramaei, A. Continuing education; lifelong learning. Procedia Soc. Behav. Sci. 2014, 116, 4052-4056. [CrossRef]

40. Gaymer, D.M. Continuing education and lifelong learning trends. In Encyclopedia of Management, 5th ed.; Helms, M.M., Ed.; Thomson Gale Publishing: Farmington Hills, MI, USA, 2006; pp. 128-131.

41. Breitbarth, W. LinkedIn Infographic-Portrait of a LinkedIn User 2016. 2016. Available online: http:/ / www.powerformula.net/ linkedininfographic-portrait-linkedin-user-2016/ (accessed on 31 January 2017).

42. Girard, A.; Fallery, B. Human resource management on Internet: New perspectives. J. Contemp. Manag. Res. 2010, 4, 1-14. 
43. Tifferet, S.; Vilnai-Yavetz, I. Self-presentation in LinkedIn portraits: Common features, gender, and occupational differences. Comput. Hum. Behav. 2018, 80, 33-48. [CrossRef]

44. Guadagno, R.E.; Muscanell, N.L.; Okdie, B.M.; Burk, N.M.; Ward, T.B. Even in virtual environments women shop and men build: A social role perspective on Second Life. Comput. Hum. Behav. 2011, 27, 304-308. [CrossRef]

45. Rui, J.; Stefanone, M.A. Strategic self-presentation online: A cross-cultural study. Comput. Hum. Behav. 2013, 29, 110-118. [CrossRef]

46. Eagly, A.H.; Wood, W. The origins of sex differences in human behavior: Evolved dispositions versus social roles. Am. Psychol. 1999, 54, 408. [CrossRef]

47. LinkedIn. Own Data and Analysis. Available online: www.linkedin.com (accessed on 18 December 2018).

48. Fiss, P.C. A set-theoretic approach to organizational configurations. Acad. Manag. Rev. 2007, 32, 1180-1198. [CrossRef]

49. Berger, E.S. Is qualitative comparative analysis an emerging method?-Structured literature review and bibliometric analysis of QCA applications in business and management research. In Complexity in Entrepreneurship, Innovation and Technology Research; Berger, E.S.C., Kuckertz, A., Eds.; Springer International Publishing: Berlin/Heidelberg, Germany, 2016; pp. $287-308$.

50. Ragin, C.C. Redesigning Social Inquiry: Fuzzy Sets and Beyond; University of Chicago Press: Chicago, IL, USA, 2009.

51. Rihoux, B.; Ragin, C.C. Configurational Comparative Methods: Qualitative Comparative Analysis (QCA) and Related Techniques; Sage Publications: Thousand Oaks, CA, USA, 2008.

52. Medina, I.; Álamos-Concha, P.; Castillo Ortiz, P.J.; Rihoux, B. Análisis Cualitativo Comparado (QCA); CIS-Centro de Investigaciones Sociológicas: Madrid, Spain, 2017; Volume 56.

53. Álvarez-Coque, J.M.G.; Mas-Verdú, F.; Roig-Tierno, N. Technological innovation versus non-technological innovation: Different conditions in different regional contexts? Qual. Quant. 2017, 51, 1955-1967. [CrossRef]

54. Ragin, C.C. Fuzzy-Set Social Science; University of Chicago Press: Chicago, IL, USA, 2000. 